\title{
THE DOUBLE-K FRACTURE CRITERION OF STEEL FIBER REINFORCED
}

\section{CONCRETE}

\author{
JINGCAI ZHANG ${ }^{*}$, QICHAO XUE ${ }^{\dagger}$ AND JIAN HE ${ }^{\dagger \dagger}$ \\ ${ }^{*}$ Harbin Engineering University, China \\ e-mail: zh_jingcai2015@163.com \\ ${ }^{\dagger}$ Harbin Engineering University, China \\ e-mail: xue1736@163.com \\ ${ }^{\dagger \dagger}$ Harbin Engineering University, China \\ e-mail: hejian@hrbeu.edu.cn
}

Key words:steel fiber reinforced concrete(SFRC);frature;crack extension resistance;double-K fracture criterion; unstable toughness;initial toughness

\begin{abstract}
Double-K fracture criterion can also describe the cracking process of steel fiber reinforced concrete well since the crack go through three stages: the stage of crack arises, expand stage, break stage.Stress intensity factor cased by bridging stress and the net stress intensity factor were given based on the hypothesis of linear asymptotic superposition.Analytical expression and a approximation algorithm for double-K fracture parameters was given as well as the crack length at a expand stage.According to the formulas offered in the paper,a new crack extension resistance theory were proposed .In the new theory, both of the cohesive force and the bridging stress were taken inio account.The theory agrees with data from published.Three-point bending experimental studies were carried out.Results show a linear increase in the $K_{I S}^{u n}$ with volume ratio ,but it not occurred to the $K_{I S}^{i n i}$.The result was in good agreement with theory.
\end{abstract}

\section{INTRODUCTION}

For many advantages, steel fiber has been used widely in the engineering structures. Recently more and more people have devoted the research of to the fracture properties of steel fiber reinforced concrete through experiment and theory analysis ${ }^{[1-8]}$.Various experiments on the fracture toughness of SFRC with different matrix mixture proportions were conducted by $\mathrm{ZHANG}^{[5]}$, computation formula of fracture toughness and volume fractions is derived. $\mathrm{Li}^{[6]}$ investigated the effect of specimen size ,as well as incision depth,on fracture toughness; fracture process of SFRC was studied by Wang;ZHANG and $\mathrm{GAO}^{[7-8]}$ adopted methods of Fracture Mechanics to analyze toughness and strength of concrete, which considers the process of slip between fibers and concrete. The method recommended by ASTM ${ }^{[9]}$ is one of the most popular fracture toughness measurement methods.However,the method was based on plain concrete, it's not clear whether the results can also apply to SFRC.Actually there are 
some research ${ }^{[5-7]}$ indicate that in most cases, quantitative analysis and accurate description is very difficult with the aforementioned method. On the other hand,research and practice results shows that current methods are not fully satisfied with the practical needs. This paper focus on Double-K fracture criterion of SFRC.

\section{Double-K fracture criterion}

\subsection{Double-K fracture criterion of plain concrete}

To establish a more convenient and accurate prediction of the crack propagation during the

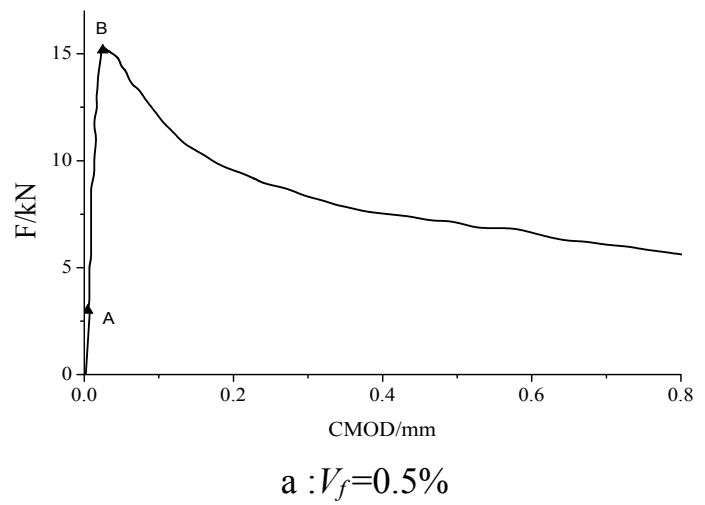

Fig. 1 typical F-CMOD curve of SFRC obtained by professor Zhang Jun

Fig. 1 is a typical $F-C M O D$ curve of SFRC obtained by professor Zhang Jun ${ }^{[13]}$. As similar to plain concrete, the crack propagation can be classified into three stages until the specimen completely broken: the stage of crack arises, expand stage and break stage.In other words, the F-CMOD curve were divide into three parts by two critical point,marked A and $\mathrm{B}$ in the diagram.At the the stage of crack arises, which correspond to the OA section in Fig.1, the crack propagation is not yet started.Results of the experiment presented a linear-relationship between $C M O D$ and F,That is to say,the specimen is mainly in elastic state with intermittent precracks. Once the crack starts to propagate, there could be a turning point,marked $\mathrm{A}$ on the $F-C M O D$ curve, the corresponding load $P_{i n i}$, denoted as initial cracking load. When the exterior load is larger than $P_{i n i}$, the expand stage, corresponding to the $\mathrm{AB}$ section, occurs. The curve is open and fracture process in concrete, the Double-K criterion were proposed by SHINGLANG $\mathrm{XU}^{[10-12]}$.This criterion consists of two independent parameters. Both of them are expressed in terms of the stress intensity factors. One of them reflects the initial cracking toughness, denoted as $K_{C}^{i n i}$, which can be can be obtained by taking the equation of LEFM.The other one were known as the unstable fracture toughness, denoted as $K_{C}^{u n}$, which also can be derived by taking the formula of LEFM.

\subsection{Crack propagation in the three-point bend SFRC beams}

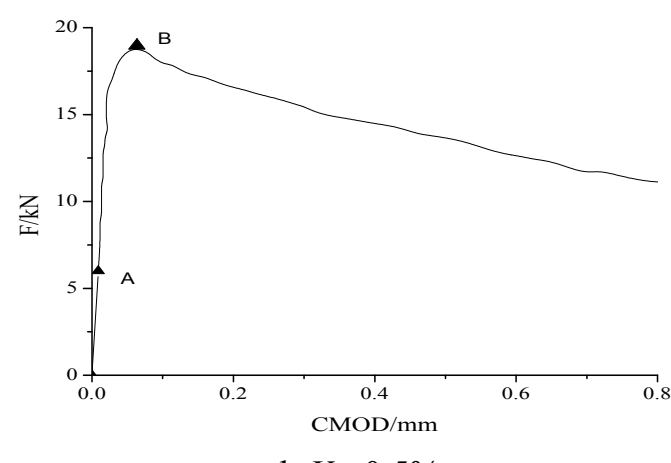

$\mathrm{b}: V_{f}=0.5 \%$ convex curve in this stage. The break stage corresponds to the descent part of curve.

The results indicates that the Double-K fracture criterion do apply to SFRC as well as plain concrete.

\subsection{Calculation of the stress intensity factor on the crack tip}

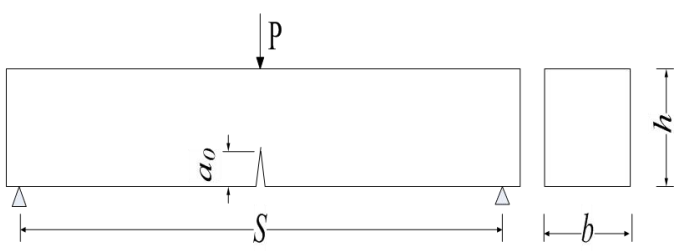

Fig.2 Three-point bending beam test sketch

Three-point bending beam test has been widely adopted by researchers.However,due to bridging stress, calculating methods proposed by $\mathrm{Xu}$ are no longer applicable.Formulas for stress intensity factor cased by bridging stress and the net stress intensity factor could be derived based on the hypothesis of linear 
asymptotic superposition and the assumption that fiber distribute SRFC randomly.

During the load process, the actual intensity factor can be evaluated by the following formula based on the hypothesis of linear asymptotic superposition,

$$
K_{I S}=K_{I S}^{P}-K_{I S}^{C}-K_{I S}^{S}
$$

where $K_{I S}^{P}, K_{I S}^{C}, K_{I S}^{S}$, represent the intensity factor caused by the external loads, cohesive force and fiber bridging, respectively.

For the three-point bending notched beams, the calculation of the $K_{I S}^{P}$ can be obtained from the following formula

$$
K_{I S}^{P}=\frac{3 P S}{2 h^{2} b} \sqrt{\pi a} g_{1}(a / h)
$$

where $P$ is the applied load; $S$ is the beam length; $b$ is the beam thickness; $h$ is the beam depth; $a$ is the crack length and $g_{1}$ is developed as follows

$$
g_{1}(a / h)=\frac{1.0-2.5 \frac{a}{h}+4.49\left(\frac{a}{h}\right)^{2}-3.98\left(\frac{a}{h}\right)^{3}+1.33\left(\frac{a}{h}\right)^{4}}{(1-a / h)^{3 / 2}}
$$

intensity factor caused by the cohesive force can be obtained using the dimensionless expression as follows

$$
\frac{K_{I S}^{C}}{f t \sqrt{h}}=Z\left(U_{e}, \frac{V_{0}}{V}\right)(1+\beta) \sqrt{\frac{V}{\pi}}\left(1-\frac{V_{0}}{V}\right) F\left(U_{e}, V\right)
$$

where

$$
U_{e}=\frac{2+\beta+(1+2 \beta) V_{0} / V}{3(1+\beta)}
$$

$K_{I S}^{C} / f t \sqrt{h}$ is easily available from tables given by $\mathrm{XU}^{[14]}$.That is to say, calculation of the stress intensity factor on the crack tip,in fact,calculation of intensity factor caused by fiber bridging.

\subsection{Calculation of the stress intensity factor caused by fiber bridging}

According to the assumption that steel fiber distribute SRFC randomly, bridging stress along the fictitious crack zone can be approximately assumed as triangular shape and illustrated as follows ${ }^{[15]}$

$$
d \sigma_{s}=\frac{\pi D_{f} \tau_{f m} L_{f} N_{u f} b}{2\left(a-a_{0}\right)} x d x
$$

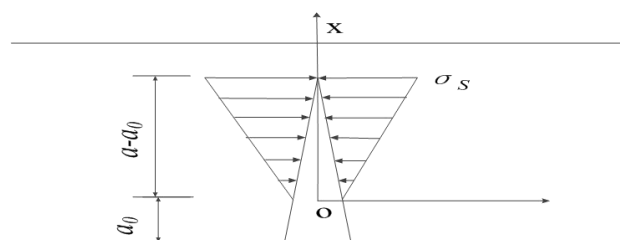

Fig.3 Bridging stress on the fictitious crack zone at the expand stage

Where $D_{f}, L_{f}$ represent the diameter and length of fiber, $\tau_{f}$ is interfacial shear strength between fiber and matrix which can be achieved by using single fiber pull-out test. $N_{u f}$ represent the amount of fiber per unit of area which can calculate by the following expression

$$
N_{u f}=\frac{8 V_{f}}{\left(L_{f}+1\right) \pi D_{f}^{2}}
$$

Given that length of specimen are much greater than height, an infinite strip subjected to a concentrated force is demonstrated in Fig.3

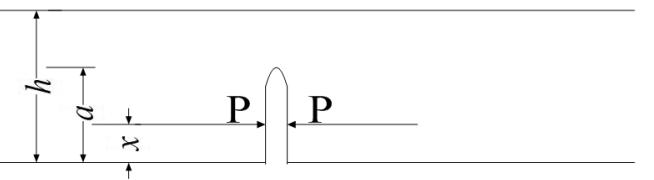

Fig.4 Single-edge cracked plate with wedge forces

The stress intensity factor, denoted as $K$, along the crack in the infinite strip of unit thickness subjected to a pair of concentrated force can be gained as following expression

$$
K=F\left(\frac{x}{a}, \frac{a}{h}\right) \frac{2 P}{\sqrt{\pi a}}
$$

where $F\left(\frac{x}{a}, \frac{a}{h}\right)$ is correction factors which expressed in a complicated form

$$
F\left(\frac{x}{a}, \frac{a}{h}\right)=\frac{3.52\left(1-\frac{x}{a}\right)}{\left(1-\frac{a}{h}\right)^{3 / 2}}-\frac{4.35-5.28 \frac{x}{a}}{\left(1-\frac{a}{h}\right)^{1 / 2}}+\left\{1-\left(1-\frac{x}{a}\right) \frac{a}{h}\right) \times\left\{\frac{1.30-0.30\left(\frac{x}{a}\right)^{3 / 2}}{\sqrt{1-\left(\frac{x}{a}\right)^{2}}}+0.83-1.76 \frac{x}{a}\right\}
$$

Correspondingly, $a \leq a_{\mathrm{c}}$, stress intensity factor cased by fiber bridging, denoted as $K_{I S}^{S}$, can be obtained as following expressions

$$
K_{I S}^{S}=\int_{a 0}^{a} 2 \sigma(x) F\left(\frac{x}{a}, \frac{a}{h}\right) / \sqrt{\pi a} d x
$$

It's the analytical expression in a way that can be made precise.However, a closed-form algorithm cant be obtained easily as a result of the singular boundary condition. Thus a simple and practical solution is badly in need.

As shown in Fig.3, the distributed fiber bridging stress is replaced by an pair of effective concentrated force on the fictitious crack zone at the critical situation.The 
concentrated force force acts on the same position as the centroid of the fiber bridging stress.That is to say the stress intensity factor caused by fiber bridging stress can be evaluate as following expressions

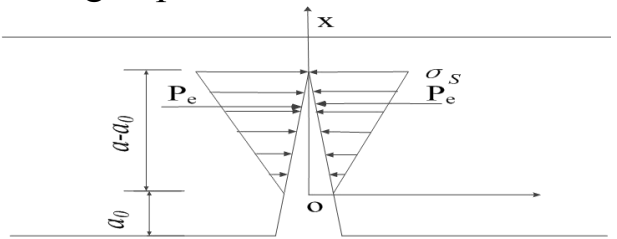

Fig.5 Effective concentrated force on the fictitious crack zone at the critical situation

$$
K_{I S}^{S}=g_{2}\left(\frac{x_{e}}{a}, \frac{a_{0}}{a}\right) \frac{2 P_{e}}{\sqrt{\pi a}} F\left(\frac{x_{e}}{a}, \frac{a}{h}\right)
$$

where $g_{2}$ is correction factors which expressed in a form proposed by Xu Shilang

$$
g_{2}\left(\frac{x_{e}}{h}, \frac{a_{0}}{h}\right)=\frac{6.15}{1+1.83\left(\frac{a_{0}}{a}-0.2\right)}\left(\frac{a_{0}}{a}\right)^{g_{3}} \sqrt{\frac{a}{\pi h}}\left(\frac{x_{e}}{h}\right)^{-0.2}
$$

Where $g_{3}$ is a piecewise function which can be obtained as follows according to $a_{0} / h$

$$
g_{3}=\left\{\begin{array}{cc}
\frac{3}{2}\left(\frac{a_{0}}{h}-0.2\right) & 0.2 \leq \frac{a_{0}}{h} \leq 0.6 \\
3\left(\frac{a_{0}}{h}-0.6\right) & 0.6 \leq \frac{a_{0}}{h} \leq 0.7 \\
6\left(\frac{a_{0}}{h}-0.7\right) & 0.7 \leq \frac{a_{0}}{h} \leq 0.8
\end{array}\right.
$$

The effective concentrated force, denote as $P_{e}$,can be evaluated as follows

$$
\begin{aligned}
P_{e} & =\int_{a_{0}}^{a} \sigma(x) d x=\int_{a_{0}}^{a} \frac{\pi D_{f} \tau_{f m} L_{f} N_{u f} b}{2\left(a-a_{0}\right)} x d x \\
& =\left(a+a_{0}\right) \pi D_{f} \tau_{f m} L_{f} N_{u f} b / 4
\end{aligned}
$$

Correspondingly, $x_{e}$ is the distance from the extending crack tip to the centroid of the fiber bridging stress and can be evaluated as follows

$$
x_{e}=a-\frac{\int_{a_{0}}^{a} t \sigma(t) d t}{\int_{a_{0}}^{a} \sigma(t) d t}=\frac{2}{3}\left(a-a_{0}\right)
$$

\section{Determination of double-K fracture parameters}

\subsection{Determination of $K_{I S}^{i n i}$}

For the three-point bending notched beams, beams, initiation toughness were defined as the intensity factor from the initial cracking load $P_{i n i}$ at the initial crack tip. The initial crack length or the prefabricated crack length,denote as $a_{0}$,can easily and accurately be measured. Once the initial cracking load is measured, $K_{I S}^{i n i}$ can be calculated can be obtained as follows.

$$
K_{I S}^{i n i}=\frac{3 P_{i n i} S}{2 h^{2} b} \sqrt{\pi a_{0}} g_{1}\left(a_{0} / h\right)
$$

Two ways are available to distinguish the initial cracking load for investigator,.One is an effective and simple option you can use. As previously mentioned,the specimen is mainly in elastic state before cracking load reached $P_{\text {ini }}$ With the F-CMOD curve,researcher may pick the inflection point or $\mathrm{A}$ in the curve from linearity to nonlinearity as the initial cracking point.The lode correspond to the inflection point is what we want.The other one is the direct method which in the experimental techniques, like the laser speckle interferometry, photoelastic coating, strain gauge technique and the acoustic emission method.However, it is not convenient and accurate. Because what these techniques measured is the surface crack rather than the interior of the specimen.In addition,someone may have no access to these measuring instruments.

\subsection{Determination of $a_{c}$}

According to the hypothesis of linear asymptotic superposition, a equation can be deduced as follows

$$
K_{I S}^{i n i}=K_{I S}^{P}-K_{I S}^{C}-K_{I S}^{S}
$$

At the critical state, a equation can also be derived

$$
K_{I S}^{P}=K_{I S}^{u n}=\frac{3 P_{\max } S}{2 h^{2} b} \sqrt{\pi a_{\mathrm{c}}} g_{1}\left(a_{c} / h\right)
$$

The analytical expression of $a_{c}$ can be obtained from (2)、(4)、(11)、(16)、(17).However, a complex equation of higher degree need to be solve. It's too complex to be applied to practical projects. Here, a straightforward method based on geometric relation would be a better choice.

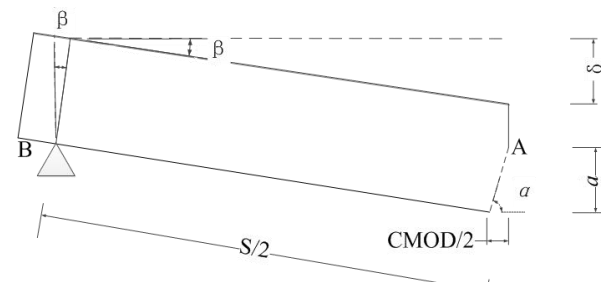

Fig.6 calculate of the the crack length 
Where geometric relation can be constructed as follows

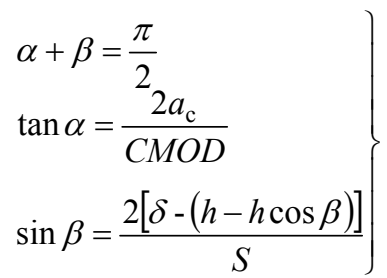

Then $a_{c}$ can be rewritten as follows

$$
a_{c}=\frac{C M O D}{2} \tan \left[\arcsin \left[\frac{2(\delta-h)}{\sqrt{S^{2}+4 h^{2}}}\right]+\arctan \left(\frac{2 h}{S}\right)\right](15-2)
$$

\section{Discussion and experimental evidence}

\subsection{Discussion}

During the hole crack propagation, the crack extension resistance SFRC,denote as $K_{R, S}$, is a concept of crack growth resistance curve was proposed by Irwin in 19 (ASTM, 1960) for a purposes to a more accurate description of crack growth,for SFRC $K_{R, S}$ can be developed as follows

$$
K_{R, S}=K_{I S}^{i n i}+K_{I S}^{S}+K_{I S}^{C}
$$

As what mentioned before, the propagation can be classified into three stages until the specimen completely broken: the stage of crack arises, expand stage and break stage.Crack extension resistance change depending on the stage.During the hole crack propagation, the crack extension resistance SFRC,denote as $K_{R, S}$, can be decomposed into three parts: the surface energy needed to overcome in the extension of cracks in the hardened cement paste, the energy consumed to resist the cohesive traction of fine and coarse aggregate in fracture zone, and the energy dissipated to overcome the fiber bridging, and can be evaluated according to the following formula.In the stage of crack arises, the surface energy in the hardened cement paste is the only source of crack extension resistance.And it is a constant.In other words, the crack extension resistance is equal to $K_{I S}^{i n i}$, in numeral.In expand stage, the crack on the specimen grows, the crack extension resistance was composed of all parts.In break stage,the stress intensity factor on the crack tip is greater than the maximum value allowed by crack extension resistance.

Researches have shown that fiber have very small influence on the surface energy in the hardened cement paste and the cohesive traction of fine and coarse aggregate in fracture zone.That is to say,for those SFRC with different steel fiber volume fraction of the same matrix, the overwhelming majority of the increase in fracture toughness is from the energy dissipated to overcome the fiber bridging.Therefor, $K_{I S}^{u n}$ can be rewritten as follows based on (16),(11)

$$
K_{I S}^{u n}=K_{I S}^{i n i}+K_{I S}^{C}+\frac{4 \tau_{f m} L_{f} b\left(a+a_{0}\right)}{\left(L_{f}+1\right) D_{f} \sqrt{\pi u}} F\left(\frac{x_{e}}{a}, \frac{a}{h}\right) g_{2}\left(\frac{x_{e}}{a}, \frac{a_{0}}{a}\right) \cdot V_{f}
$$

According to (20), a linear relation between $K_{I S}^{u n}$ and $V_{f}$ can be investigated.

\subsection{Experimental evidence}

Many experiment on fracture property of SFRC with the methods recommend by ASTM has been carried by researchers. The results named fracture toughness, denote as $K_{I C}$, which roughly synonymous with $K_{I S}^{u n}$, were achieved. That is,the experiment result will present a linear-relationship between $K_{I C}$ and $V_{f}$.

Table 1shows the experimental data reported in [2] and [4] ,Fig.6 clearly shows correctness correctness and universal applicability of the theory presented in this paper. In particular, the matrix of reference [2] were high strength concrete while what of reference [4] were low strength.The results indicate that theory proposed in this paper can be applied to SFRC no matter how the matrix changes.

Table 1:Result report in [2] [4]

\begin{tabular}{cccccccccccc}
\hline ref. & $V_{f} \%$ & $a_{0} / h$ & $K_{I C} / \mathrm{MPa} / \mathrm{m}^{2}$ & ref. & $V_{f} \%$ & $a_{0} / h$ & $K_{I C} / \mathrm{MPa} / \mathrm{m}^{2}$ & ref. & $V_{f} \%$ & $a_{0} / h$ & $K_{I C} / \mathrm{MPa} / \mathrm{m}^{2}$ \\
\hline$[2]$ & 0.5 & 0.20 & 7.392 & {$[2]$} & 0.5 & 0.40 & 4.100 & {$[4]$} & 0.0 & 0.33 & 0.867 \\
{$[2]$} & 1.0 & 0.20 & 7.997 & {$[2]$} & 1.0 & 0.40 & 5.041 & {$[4]$} & 0.5 & 0.33 & 0.956 \\
{$[2]$} & 1.5 & 0.20 & 8.247 & {$[2]$} & 1.5 & 0.40 & 7.104 & {$[4]$} & 1.0 & 0.33 & 1.149 \\
{$[2]$} & 2.0 & 0.20 & 8.909 & {$[2]$} & 2.0 & 0.40 & 7.637 & {$[4]$} & 1.5 & 0.33 & 1.386 \\
\hline
\end{tabular}




\begin{tabular}{llllllllllll}
\hline$[2]$ & 0.5 & 0.30 & 6.360 & {$[4]$} & 0.0 & 0.17 & 0.987 & {$[4]$} & 0.0 & 0.50 & 0.813 \\
{$[2]$} & 1.0 & 0.30 & 6.454 & {$[4]$} & 0.5 & 0.17 & 1.120 & {$[4]$} & 0.5 & 0.50 & 0.915 \\
{$[2]$} & 1.5 & 0.30 & 7.506 & {$[4]$} & 1.0 & 0.17 & 1.320 & {$[4]$} & 1.0 & 0.50 & 1.079 \\
{$[2]$} & 2.0 & 0.30 & 8.035 & {$[4]$} & 1.5 & 0.17 & 1.472 & {$[4]$} & 1.5 & 0.50 & 1.269 \\
\hline
\end{tabular}
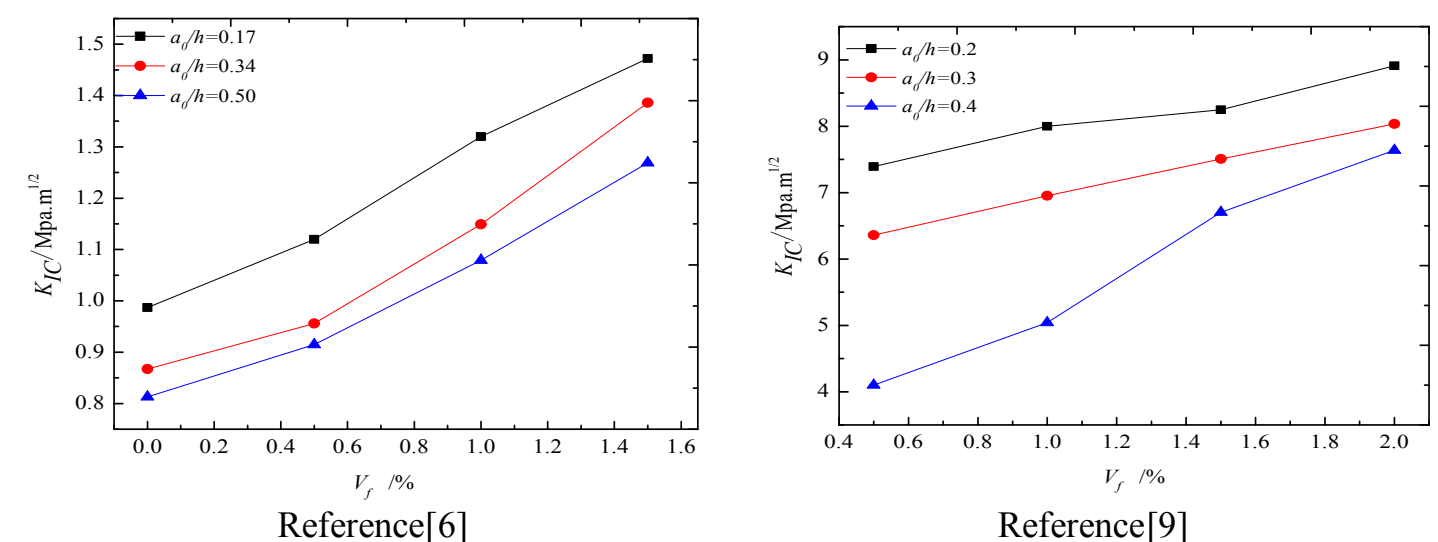

Fig.7:curves report in [6] and [9]

\section{Experimental verification}

Three-point bending experimental of SFRC with vary content of steel fiber were conducted to verify the theory.

\subsection{Materials and mix proportions}

Chinese standard Portland cement,river sand with fineness modulus of 3.12, and limestone with diameter of 7-21 mm and shear-pattern steel fiber with length of $30 \mathrm{~mm}$ were adopted to prepare SFRC specimens. A series SFRC specimens with additions(by volume) of $0.5 \%, 0.75 \%, 1.00 \%, 1.25 \%, 1.50 \%, 1.75 \%$ and $2.00 \%$ steel fiber,denoted as A,B,C,D,E,F, $\mathrm{G}, \mathrm{H}$, respectively, were prepared.All SFRC specimens share the same mix proportions matrix concrete, see Table 2.

For each mixture, 5 specimens of $100 \mathrm{~mm} \times$ $100 \mathrm{~mm} \times 515 \mathrm{~mm}$ with precrack $(40 \mathrm{~mm})$ for three-point bending test and 3 specimens of 150 $\mathrm{mm} \times 150 \mathrm{~mm} \times 150 \mathrm{~mm}$ for compress strength experiments were prepared. The average values were used to determine the final result.Exper experiment was conducted at the center of mechanics experiment ,Harbin Engineering University.
Table 2 Mix proportions of matrix concrete $\left(\mathrm{kg} / \mathrm{m}^{3}\right)$

\begin{tabular}{ccccc}
\hline Cement & Sand & $\begin{array}{c}\text { Coarse } \\
\text { aggregate }\end{array}$ & Water & $\begin{array}{c}\text { Water } \\
\text { reducer }\end{array}$ \\
\hline 427 & 196 & 717 & 1150 & 3 \\
\hline
\end{tabular}

\subsection{Test results and discussion}

The crack propagation can be see in Fig.8.And Table 3 and Fig. 9 shows the test results about $K_{I S}^{u n}, K_{I S}^{i n i}, a_{\mathrm{c}}$ and compressive strength(denote as $\left.f_{c u}\right)$.As the increase of steel fiber, $K_{I S}^{i n i}$ were improved on the whole.But the effect was not remarkably.In stage of crack arises,specimen mainly in elastic state,steel fiber didn't have much effect on specimen without overt linear relationship.However, there are many different factors that can influence, for instance characteristic pore.Therefor,on one hand ,steel fiber may improve the working performance of SFRC but on the other hand, the steel fiber concrete may also change the gap and compactness of SFRC.Both of them result in the experimental data obtained.These results are in agreement with those reported in literature[22,23].The $K_{I S}^{u n}$ improved with the increase of volume percentage of fiber, and indicates obvious linear relationship. The results proved that the theory of the article is feasible and correct. 


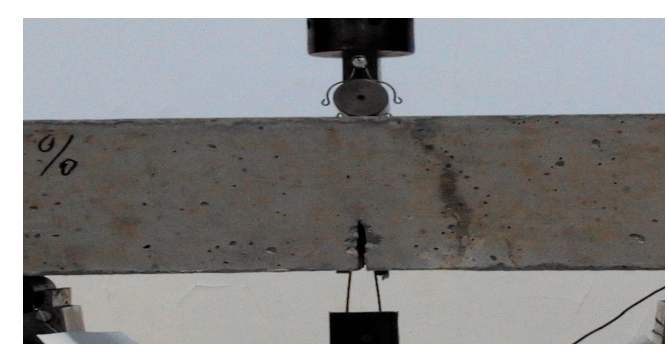

a:elastic state

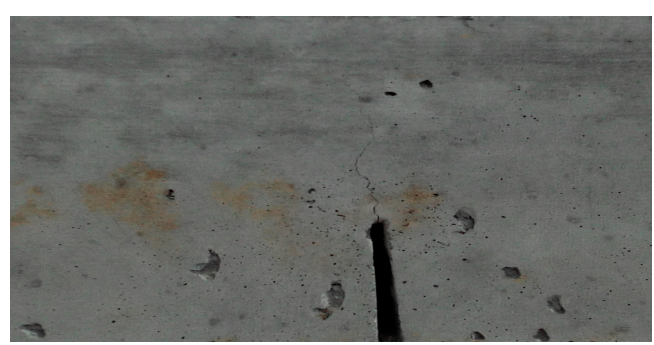

c:expand stage

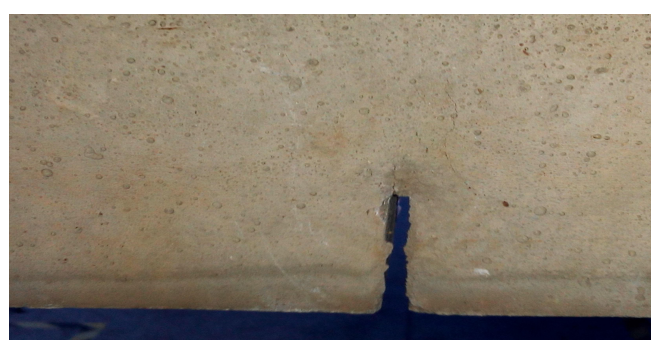

b:crack arises

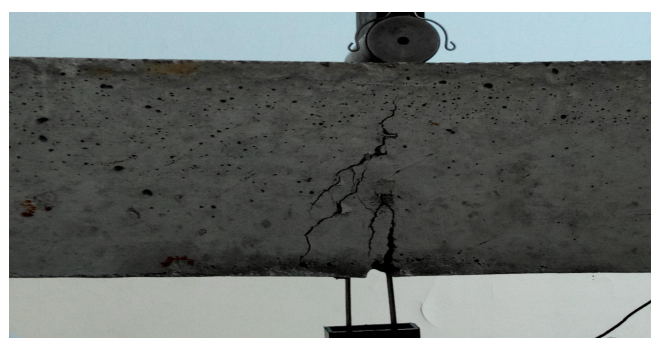

d:break situation

Fig.8:The crack propagation

Table 3 Result of experiment

\begin{tabular}{cccccccccccc}
\hline \multirow{2}{*}{ series } & $\begin{array}{c}V_{f} \\
\%\end{array}$ & $\begin{array}{c}K_{I S}^{\text {ini }} \\
\mathrm{MPa} / \mathrm{m}^{2}\end{array}$ & $\begin{array}{c}a_{c} \\
\mathrm{~mm}\end{array}$ & $\begin{array}{c}K_{I S}^{u n} \\
\mathrm{MPa} / \mathrm{m}^{2}\end{array}$ & $\begin{array}{c}f_{c u} \\
\mathrm{MPa}\end{array}$ & series & $\begin{array}{c}V_{f} \\
\%\end{array}$ & $\begin{array}{c}K_{I S}^{\text {ini }} \\
\mathrm{MPa} / \mathrm{m}^{2}\end{array}$ & $\begin{array}{c}a_{c} \\
\mathrm{~mm}\end{array}$ & $\begin{array}{c}K_{I S}^{u n} \\
\mathrm{MPa} / \mathrm{m}^{2}\end{array}$ & $f_{c u}$ \\
\hline $\mathrm{A}$ & 0.25 & 0.711 & 59.95 & 1.520 & 40.56 & $\mathrm{E}$ & 1.25 & 0.777 & 73.45 & 2.476 & 49.76 \\
$\mathrm{~B}$ & 0.50 & 0.722 & 62.43 & 1.725 & 43.77 & $\mathrm{~F}$ & 1.50 & 0.785 & 76.88 & 2.83 & 49.97 \\
$\mathrm{C}$ & 0.75 & 0.734 & 65.56 & 1.894 & 44.98 & $\mathrm{G}$ & 1.75 & 0.783 & 77.95 & 3.043 & 54.98 \\
$\mathrm{D}$ & 1.00 & 0.762 & 69.32 & 2.154 & 47.43 & $\mathrm{H}$ & 2.00 & 0.797 & 80.34 & 3.205 & 57.23 \\
\hline
\end{tabular}

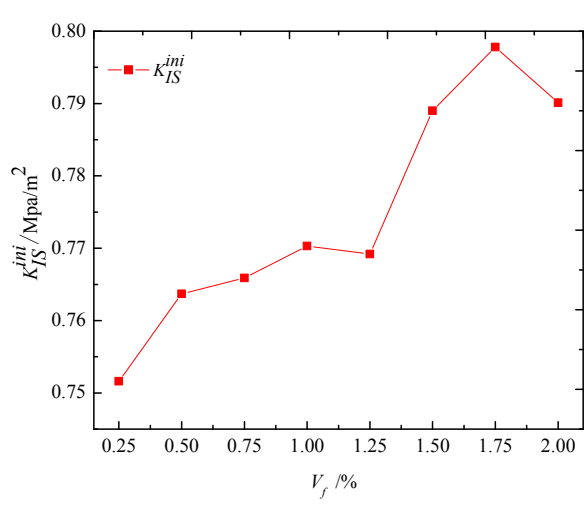

$\mathrm{a}: K_{I S}^{\text {ini }}$

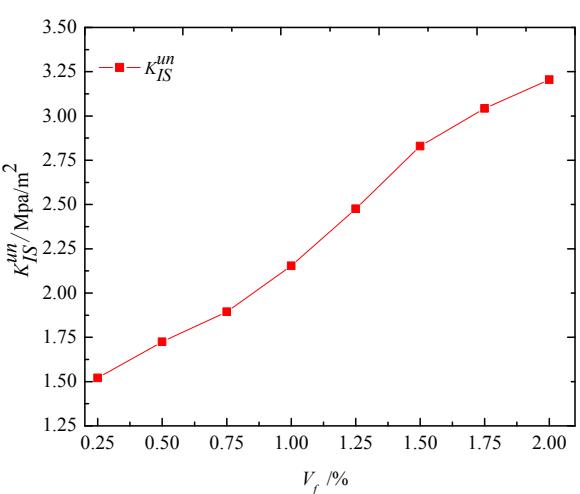

b: $K_{I S}^{u n}$

Fig.9:curves of $K_{I S}^{i n i}$ and $K_{I S}^{u n}$

\section{CONCLUSIONS}

Double-K fracture parameters can also describe the crack propagation of SFRC well.A new Double-K fracture parameters which apply to SFRC is derived.A relatively full-fledged theory and computing method is built.In addition, unstable fracture toughness would nearly for increases in volume ratio.However, it wouldn't occur to the initiation toughness 
according to analysis. Analyses of the datum got by previous researcher indicates that the new Double-K fracture parameters present in this paper can be directly used to depict SFRC's crack propagation with a satisfactory accuracy. At last, three-point bending experimental were carried out and the results verify the validity of theoretical analyses.

\section{ACKNOWLEDGMENT}

This paper is funded by the International Exchange Program of Harbin Engineering University for Innovation-oriented Talents Cultivation.And supported by National Natural Science Foundation of China (51409056),Natural Science Foundation of Heilongjiang Province (E2015047) and the Fundamental Research Funds for the Central Universities(HEUCF150202).

\section{REFERENCES}

[1] FU Ch.,MA Q.,JIN X..Fracture property of steel fiber reinforced concrete at early age[J].Computers and Concrete,13, 1,2014:31-47

[2] Dorraj,S.,Mojtaba,M.B.Compressive,flexur and abrasive performance of steel fiber reinforced concrete[J]. Journal of Mechanical Engineering Research and Developments, 37, 1,2014:1-10.

[3] Krmi, J..Experimental Investigation of the Fracture of Hybrid-Fiber-Reinforced Concrete[J].Mechanics of Composite Materials, 18,3,2015:241-252.

[4] Yoo, Doo-Yeol;Shin, Hyun-Oh; Yang, Jun-Mo.Material and bond properties of ultra high performance fiber reinforced concrete with micro steel fibers[J]. Composites Part B: Engineering, 58,2014: 122-133.

[5] ZHANG T.,GAO D.,ZHENG G.,ZHU H..Fracture toughness of concrete and influencing factors under three-point bending[J].Journal of Hydraulic Engineering,5,2013:601-607

[6] LI W..Experimental Analysis of Fracture Properties of Steel Fiber Reinforced Concrte[J].Transportation \& Science Technology.1,2010:84-86.
[7] GAO D.,ZHANG T..Fracture energy of steel fiber reinforced high strength concrete under the three-point bending[J] Journal of Hydraulic Engineering 2007,9:1115-1122.

[8] ZHANG T.,LI Q.,WANG Z.. Fracture Toughness of Steel Fiber Reinforced High Strength Concrete and the Influencing Factors[J]. Journal of the Chinese Ceramic Society, 5,2012: 638-645.

[9] ASTM. E647-11 Standard Test Method for Measurement of Fatigue Crack Growth Rates [S].United States, 2011.

[10]XU, S.; Reinhardt, H.W. Determination of double-K criterion for crack propagation in quasi-brittle fracture, Part I: experimental investigation of crack propagation[J].International Journal of Fracture, 98,2, 1999: 111-149.

[11] XU, S.; Reinhardt, H.W. Determination of double-K criterion for crack propagation in quasi-brittle fracture, Part II: Analytical evaluating and practical measuring methods for three-point bending notched beams[J].International Journal of Fracture, 98(2), 1999,: 151-177

[12]XU, S.; Reinhardt, H.W. Determination of double-K criterion for crack propagation in quasi-brittle fracture, Part III: compact tension specimens and wedge splitting specimens [J].International Journal of Fracture, 98(2),1999: 179-193.

[13]ZHng J.,CHEN C..Design of steel fiber reinforced concrete based on stress crack opening relationship[J].Journal of Southeast University ,40,2010:1-9.

[14]XU, S.; Reinhardt, H.W..A simplified method for determining double-K fracture parameters for three-point bending tests[J].International Journal of Fracture, 2000, 98(2): 181-209.

[15] Wu X G, Han S M, Kim S W, Kang S T. Shear failure load of SFR-UHPCC I-beam without stirrup based on limit analysis of concrete plasticity [J]. Key Engineering Materials, 2006, 324: 491-494. 